\title{
Spectrophotometric determination of selenium in various samples using 5,6-diaminouracil hydrochloride (DAUH)
}

\author{
Salwa Fares Raasi \\ Department of Chemistry, Faculty of Sciences, University of Al- Baath Homs \\ Mobile: 00963-966-243153 \\ E-mail address: salwarassi@gmail.com
}

Keywords: Selenium determination, spectrophotometry, 5,6-diaminouracil hydrochloride (DAUH) ,

\begin{abstract}
A simple, rapid and sensitive spectrophotometric method was developed for the determination of Se (IV) using 5,6-diaminouracil hydrochloride (DAUH) as an analytical reagent. The reagent has been synthesized and characterized using IR, 1H NMR. The metal ion in aqueous medium forms yellow colored complex with DAUH showing maximum absorbance at $343 \mathrm{~nm}$. Hence, analytical studies were further carried out at $343 \mathrm{~nm}$. The reagent reacts with selenium in acidic medium to form yellow colored 1:1 (M:L) complex. The color reactions are instantaneous and absorbance values remain constant for one week. The composition of the Se (IV) complex with DAUH was studied by the method of job's continuous variation and molar ratio method. Beer's law was obeyed in the range $0.2-15.0 \mu \mathrm{g} \mathrm{mL} \mathrm{m}^{-1}$ of Se (IV). The molar absorptivity and Sandell's sensitivity of the method were found to be $0.5 \times 10^{+4} \mathrm{~L} \cdot \mathrm{mol}^{-1} . \mathrm{cm}^{-1}$ and $0.031 \mu \mathrm{g} . \mathrm{cm}^{-2}$ respectively. Since DAUH method is more sensitive, it was applied for the determination of selenium in samples.
\end{abstract}

\section{INTRODUCTION}

Spectrophotometric methods is one of the most important ways, which is used in analytical chemistry, because it wide used in researches field, and has sensitivity, accuracy, simplify and low cost, The diversity UV-Vis. analysis (direct, extraction, kinetic...etc) by using organic reagents make it possible to determine a lot of elements in many analytical samples

Selenium is an essential trace nutrient and selenium deficiency diseases are well known in veterinary medicine. Above trace levels, ingested selenium is toxic to animals and may be toxic to humans. The selenium concentration of most drinking waters and natural waters is less than $10 \mu \mathrm{g}$ $\mathrm{mL}^{-1}$. Selenium is widely distributed in nature, in relatively small concentrations in rocks, plants, coal and other fossil fuels. Selenium enters into natural water through seepage from splendiferous soil and industrial waste. Selenium compounds have extensive applications and because of its significance, several analytical techniques have been reported for the determination of selenium, which includes spectro-fluorometry, electro thermal atomic absorption spectrometry, hydride generation, polarography, cathode-stripping voltammetry, radiochemical neutron activation analysis, and flow- injection techniques [1]. There are many reagents available for the spectrophotometric determination of selenium., among which, the recently used were $\mathrm{J}$-acid [2], Leuco crystal violet [3], resazurin [4], sodium salt of hexamethyleneimine carbodithioate [5], 1naphthylamine-7-sulphonic acid [6], variamine blue [7]. When selenium is present in animal feeds at a concentration less than $0.1 \mathrm{mg} \mathrm{L}^{-1}$, deficiency symptoms develop, but when present at a higher concentration, exceeding $5 \mathrm{mgL}^{-1}$, chronic selenosis occurs. Selenium tends to weaken the toxic action of some heavy metals in animal and human organisms [8-9].

Selenium is widely distributed in the environment (waters, soil, and air) albeit generally in very low concentrations $(\leq 1 \mu \mathrm{g} / \mathrm{g})$. Selenium is a naturally occurring element found in rocks[10], soil, water, air and animals. Selenium is a trace mineral that is essential to good health but required only in small amounts [11-13]. Selenium is incorporated into proteins to make selenoproteins, which are important antioxidant enzymes. The antioxidant properties of selenoproteins help to prevent cellular damage from free radicals.. Other selenoproteins help regulate thyroid function and play a role in the immune system [14-16]. Selenium compound are widely used in paints, dyes, glass electrical, rubber, insecticides, and many other industries. Some industrial and agricultural 
processes release selenium as a by-product and selenium from such sources has caused environmental disaster [17]. The threshold limit value for selenium compounds in air is $0.1-0.2 \mathrm{mg}$ $\mathrm{dm}^{-3}$ in water it is $4.0 \mathrm{ppm}$. The toxicity, availability and environmental mobility of selenium are very much dependent on its chemical form [18]. Selenium can occur in different oxidation states in organic and inorganic compounds. In many environmental matrixes, e.g. natural water and soils, the predominant oxidation state of selenium are Se (IV) and Se (VI). Selenium is also reported to be present in cigarette paper, tobacco [19] and various cosmetic samples [20]. Because of its significance, several analytical techniques have been reported concerning the determination of selenium [21-24].

Plant foods are the major dietary sources of selenium in most countries throughout the world. The content of selenium in food depends on the selenium content of the soil where plants are grown or animals are raised.

In the present study, we are reporting rapid, simple, sensitive and selective methods for the determination of traces of selenium (IV) with DAUH, anew reagent.

This paper describes synthesis, characterization and analytical properties of new reagent (DAUH). Since the reagent is more sensitive, it is used for the determination of selenium in various samples.

\section{EXPERIMENTAL}

\subsection{Apparatus}

A Jasco V-530 UV-VIS spectrophotometer (Japan) with $1 \mathrm{~cm}$ quartz cells was used for all absorbance measurements under the following operating conditions: scan speed medium (400 $\mathrm{nm} / \mathrm{min}$ ), scan range $200-1100 \mathrm{~nm}$ and slit width $2 \mathrm{~nm}$. Spectra were automatically obtained by Jasco system software. pH measurements were made with ORION 250A (USA) with combined glass $\mathrm{pH}$ electrode.

NMR Spectrometry Bruker 400MHz, FT-IR 4100 (Fourier transform infrared spectrometer) Jasco the results of the suggested method were coincidental with the analysis data of the same samples with the Hydride Generation-Atomic Absorption technique as a comparative method

\subsection{Reagents and materials}

All chemicals used were of analytical-reagent grade of the highest purity available procured from Merck. Doubly distilled de-ionized water was used throughout the experiment.

\subsection{Preparation of reagent (DAUH)}

DAUH was prepared In flask equipped with a reflux condenser and an efficient stirrer is placed $500 \mathrm{~mL}$ of absolute $(99.8 \%)$ ethanol. To this is added $19.7 \mathrm{~g}$. (1.72 g. atom) of sodium, and, after solution is complete, $45.57 \mathrm{ml} .(48.65 \mathrm{~g} ., 0.86 \mathrm{~mole})$ of ethyl cyanoacetate and $50.60 \mathrm{~g}$. (0.86 mole) of urea are added. The mixture is heated 4 hours, At the end of the reaction time, $500 \mathrm{~mL}$ of hot $\left(80^{\circ}\right)$ water is added., the stirred mixture is heated at $80^{\circ}$ for 15 minutes and is then neutralized. Additional glacial acetic acid $(37.5 \mathrm{ml}$.) is added.STEP(1), followed by cautious addition of a solution of $32.4 \mathrm{~g}$. ( 0.94 mole) of sodium nitrite dissolved in $35 \mathrm{ml}$. of water. The dark red nitroso compound separates almost immediately.

The slurry is stirred while being heated on a steam bath, and solid sodium hydrosulfite is added until the red color of the nitroso compound is completely bleached. Then an additional $15 \mathrm{~g}$ of sodium hydrosulfite is added; the light tan suspension is stirred with heating for 15 minutes more and is allowed to cool. The dense 5,6-diamino- Uracil bisulfite is filtered from the cooled solution, washed well with water, and partially dried.

Concentrated hydrochloric acid is added until the consistency of the resulting mixture is such as to permit mechanical stirring (50 to $100 \mathrm{ml}$. of acid). The slurry is heated on a steam bath with stirring for 1 hour. The tan 5,6-diamino Uracil hydrochloride is filtered, washed well with acetone, and vacuum-dried over phosphorus pentoxide. The yield of 5,6-diamino- Uracil hydrochloride is. (90\%). (Figure 1). 


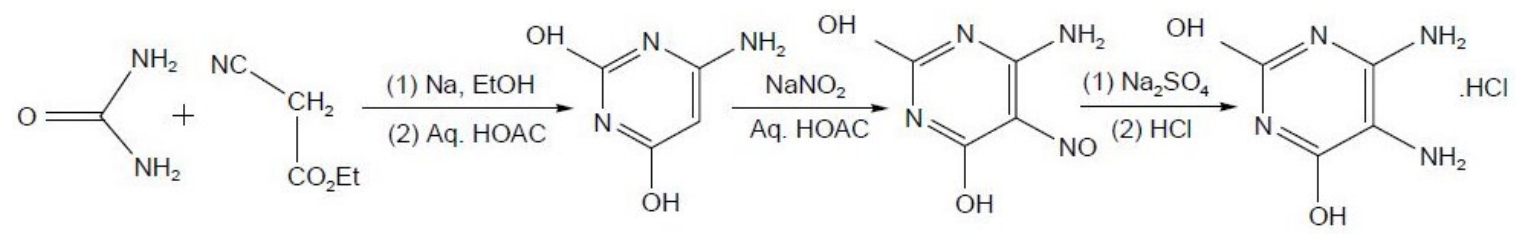

Figure 1. Synthesis of DAUH.

\subsection{Characterization of reagent DAUH}

The reagent has been synthesized and characterized by IR, 1HNMR data. Infrared spectrum of DAUH shows bands at $3409,3404-3285,1695,1715,1665,1197,1329$, respectively corresponding to $v(\mathrm{O}-\mathrm{H}) \vee\left(\mathrm{NH}_{2}\right),(\mathrm{C}=\mathrm{N}), v(\mathrm{C}=\mathrm{O}),(\mathrm{C}=\mathrm{C})(\mathrm{C}-\mathrm{C}),(\mathrm{C}-\mathrm{N})$

H1NMR spectrum of DAUH $\left(\mathrm{CDCl}_{3}+\mathrm{DMSO}\right)$ showed signals at $8.00(6 \mathrm{H}), 11.53(1 \mathrm{H})$, 7.83(1H), due to $\mathrm{C}_{5}-\mathrm{NH}_{3}{ }^{+}, \mathrm{C} 6-\mathrm{NH}_{3}{ }^{+}, \mathrm{C} 1-\mathrm{OH}, \mathrm{C} 3-\mathrm{OH}$. The molecular formula of the reagent is $\mathrm{C}_{4} \mathrm{H}_{8} \mathrm{~N}_{4} \mathrm{O}_{2} \mathrm{Cl}_{2}$ (M.Wt, 187).(Figure 2).

\section{5. pKa values of reagents}

The $\mathrm{pKa}$ values were determined by recording the UV-Visible spectra of $1 \times 10^{-4} \mathrm{M}$ solutions of the reagent at various $\mathrm{pH}$ values and by taking the arithmetic mean of the values obtained from the measurements at different wave lengths determined spectrophotometrically depended on reference analytical methods (half height, Limit absorbance and Colleter's). The values of deprotonation of DAUH were $(4.63,8.14$ and 10.62)<smiles>Nc1nc(O)nc(O)c1NCl</smiles>

Figure 2. DAUH - Structure

\subsection{DAUH solution}

A $1 \times 10^{-2} \mathrm{M}$ solution was prepared by dissolving $0.0187 \mathrm{~g}$ of DAUH in $100 \mathrm{ml}$ of water. containing few drops of conc.HCl, The reagent solution is stable for at least $24 \mathrm{~h}$.

\subsection{Se (IV) solution}

A $1 \times 10^{-2} \mathrm{M}$ stock solution of selenium was prepared by dissolving $0.1890 \mathrm{~g}$ of sodium selenate $\mathrm{Na}_{2} \mathrm{Seo} 4$ (Merck Darmstadt) in double distilled water containing few drops of conc. $\mathrm{H}_{2} \mathrm{SO}_{4}$ and made up to the mark in a $100 \mathrm{~mL}$ volumetric flask. Aliquots of this solution were standardized with EDTA titration using xylenol orange as an indicator. Dilute solutions were prepared from this stock solution.

\subsection{Procedure for Preparation of water samples}

Different water samples were collected from various places. The samples $(150 \mathrm{ml})$ were stored at $5 \mathrm{oC}$ in metal free polyethylene bottles. Water samples were filtered through whatman filter paper no. 41 and collected into $250 \mathrm{ml}$ beakers. All the filtered environmental water samples were evaporated nearly to dryness with a mixture of $10 \mathrm{ml}$ con $\mathrm{HNO}_{3}$ and $5 \mathrm{ml}$ of con $\mathrm{H}_{2} \mathrm{SO}_{4}$ and then cooled to room temperature. The sample was digested in the presence of an excess potassium permanganate solution according to the method recommended by Fifiled et al.,5. The residues were 
then heated with $10 \mathrm{ml}$ of deionized water in order to dissolve the salts. The solutions were cooled and neutralized with dilute $\mathrm{NH}_{4} \mathrm{OH}$. The digest was transferred into a $25 \mathrm{ml}$ calibrated flask and diluted up to the mark with deionized water.

\subsection{Procedure for Preparation of various samples}

To determine selenium in Yellow Corn, Peas, Chick-pea, Wheat, Almond. Takes 1-4 grams of the sample after crushed and put in Arlanmayr hydride generating device, and add to $20 \mathrm{ml}$ of distilled water, then slowly mix, were heated on electric heater for 10 minutes while stirring, then cooled resulting solution and add $10 \mathrm{~mL}$ of tin chloride solution $\mathrm{SnCl} 2.2 \mathrm{H} 2 \mathrm{O}(0.33 \% \mathrm{HCl}$ in the center) and $5 \mathrm{ml}$ of potassium iodide solution ( $0.15 \%$ ), leaves the mixture for 5 minutes, add $10 \mathrm{ml}$ of alcohol (to reduce the foam produced during the reaction), then add 8 grams metal of zinc, device Closing to collect hydride in another Arlanmayr that contains $2 \mathrm{~mL} 0.5 \mathrm{M} \mathrm{NaOH}$ and $2 \%$ water Oxygen, leaves the reaction for an hour to two hours. For the Liberation of selenium, according to the sample type used. Then take sodium hydroxide which brought together the element for Determine the selenium in sample.

\subsection{Preparation of the calibration graph}

An aliquot of the stock solution containing 1.0-200 $\mu \mathrm{M}$ of selenium (IV) was transferred into a $25 \mathrm{~mL}$ volumetric flask. Hydrochloric acid $(10 \mathrm{~mL}$ of $5 \mathrm{M})$ and DAUH $\left(2.5 \mathrm{~mL}\right.$ of $\left.10^{-3} \mathrm{mM}\right)$ were added. The solution was diluted up to the mark with distilled water and mixed well. The absorbance of the solution was measured after about 30 minutes at $343 \mathrm{~nm}$ against a reagent blank. The amount of selenium in the sample solution was then deduced from the calibration graph.

\section{RESULTS AND DISCUSSION}

Selenium reacts with 5,6-diaminouracil hydrochloride (DAUH) in hydrochloric acid solution 1:1 and gives yellow colored complex. The complex has a maximum absorbance at $343 \mathrm{~nm}$. The optimum reaction conditions for the quantitative determination of the metal-ligand complex was established through a number of preliminary studies, such as the effect of acidic medium, reagent concentration, interference of foreign ions, in order to develop a rapid, selective and sensitive spectrophotometric method for the determination of selenium (IV) at microgram levels.

\subsection{Absorption spectra of the reagent and Se (IV)-DAUH complex}

Absorption spectra of Se (IV)-DAUH complex and reagent show maximum absorbance at $343 \mathrm{~nm}$ and $260 \mathrm{~nm}$, respectively (Figure 3). The reagent showed minimum absorbance at the wavelength of maximum absorbance of the complex. Hence, all the spectral measurements of the complex were therefore carried out at $360 \mathrm{~nm}$.

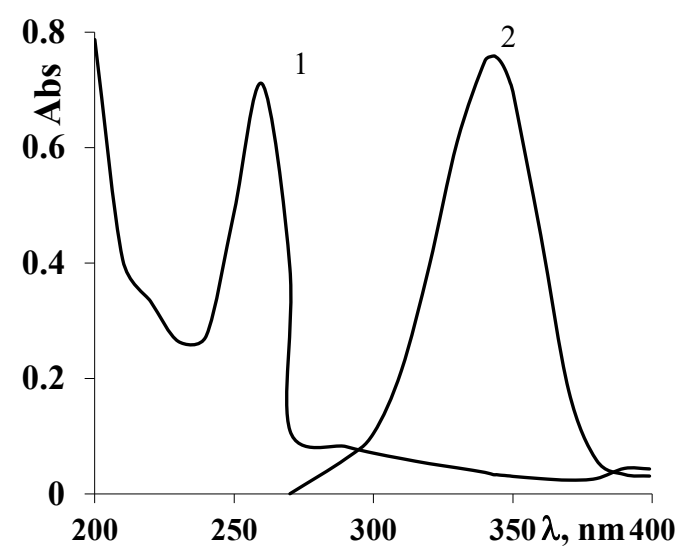

Figure 3., (1) Absorption spectra of reagent (2) Absorption spectra of Se-DAUH complex 


\subsection{Optimization of reaction conditions}

The spectrophotometric properties of the colored product as well as the different experimental parameters affecting the color development and its stability were studied and optimized by changing each variable in turn, while keeping all others constants. In all experiments.

\subsection{Effect of. hydrochloric acid, concentration.}

From hydrochloric acid, phosphoric acid and sulphuric acid, the first gave the highest absorbance and stability. The study of the effect of acidity on the color intensity of the reaction mixture showed that the constant and maximum color is obtained in the range $1.6-2.8 \mathrm{M}$, the. At concentrations higher than $2.8 \mathrm{M}$ and lower than $1.6 \mathrm{M}$ the absorbance decreases significantly. The working $\mathrm{HCl}$ concentration selected for the formation and fixation of the complex at $2 \mathrm{M}$. The optimum $\mathrm{HCl}$ concentration is the same for all sample volumes studied. (Figure 4). The maximum intensity of the yellow color was achieved in the range of 5.5-10 $\mathrm{ml}$ concentrated hydrochloric acid. Therefore, $10 \mathrm{ml}$ of hydrochloric acid $2 \mathrm{M}$ was used for the better results.

\subsection{Effect of reagent concentration}

All analytical studies were therefore, carried out at $\left(\mathrm{C}_{\mathrm{HCl}}=2.0 \mathrm{M}\right)$. Different volume of molar excess of DAUH was added to fixed Se (IV) concentration and the absorbance's were measured adopting the standard procedure. It was observed that 100 fold molar excess of reagent with respect to metal ion is necessary to get maximum absorbance. Hence, a 100 fold molar excess of reagent was used for further experimental studies. The absorbance of the solution was measured at different time intervals to ascertain the time stability of the color complex.
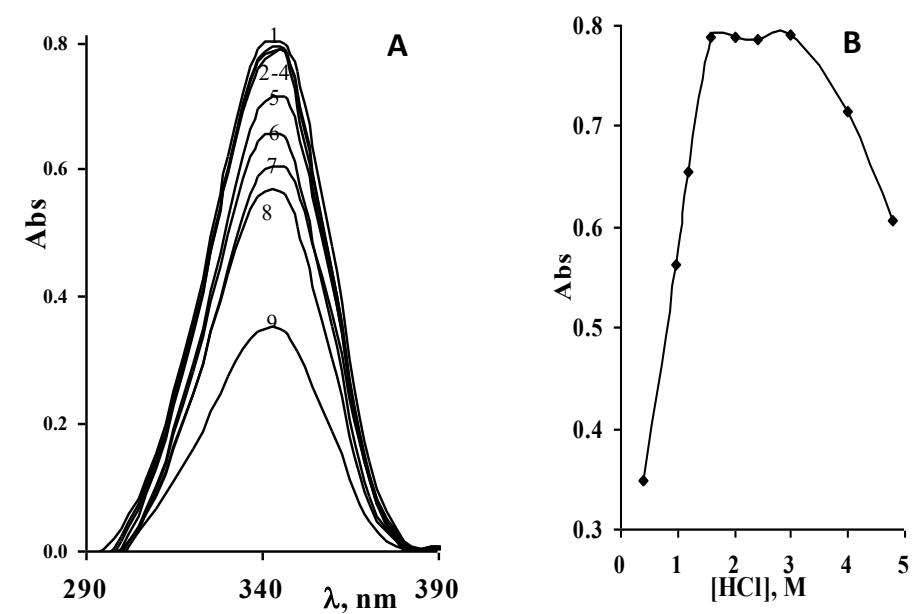

Figure 4. A - Absorption spectra in varing $\mathrm{HCl}$ molarity.

B - the $\mathrm{HCl}$ molarity effect on the absorbance of the formed complex Se(IV)-DAUH.

\subsection{Time, Temperature and Color Stability}

Under the optimized conditions, although the color developed instantaneously, 30 min were allowed to obtain the maximum and constant absorbance in the method. The yellow colored product was stable for one week. The absorbance varied by not more than $1 \%$ over a period of two days for the method and color development was independent of temperature in the range of $25{ }^{\circ} \mathrm{C}-45{ }^{\circ} \mathrm{C}$

\subsection{Analytical method validation}

\subsubsection{Calibration, graph reproducibility and detection limit}

Using the optimized composition and conditions described above. The effect of the Se concentration was studied over $1.00-200.0 \mu \mathrm{M}$ for convenience of the measurement. The calibration curves gave an excellent linear for $(2.5-189 . .9 \mu \mathrm{M}),(0.2-15 \mu \mathrm{g} / \mathrm{mL})$, as shown in (Fig 5) at $343 \mathrm{~nm}$, 
The molar absorption coefficient and the Shandell's sensitivity were found to be $0.5 \times 10^{4} \mathrm{~L} \mathrm{~mol}^{-1}$ $\mathrm{cm}^{-1}$ and $0.031 \mu \mathrm{g} \mathrm{cm}^{-2}$ of Se respectively. The selected analytical parameters obtained are summarized in Table 1.

\subsubsection{Precision and accuracy}

The precision and accuracy of the method was studied by analysing solutions containing known amounts of Se (IV) within the Beer's law limit. Percentage relative standard deviation (RSD \%) as precision and percentage recovery as accuracy of the suggested method were
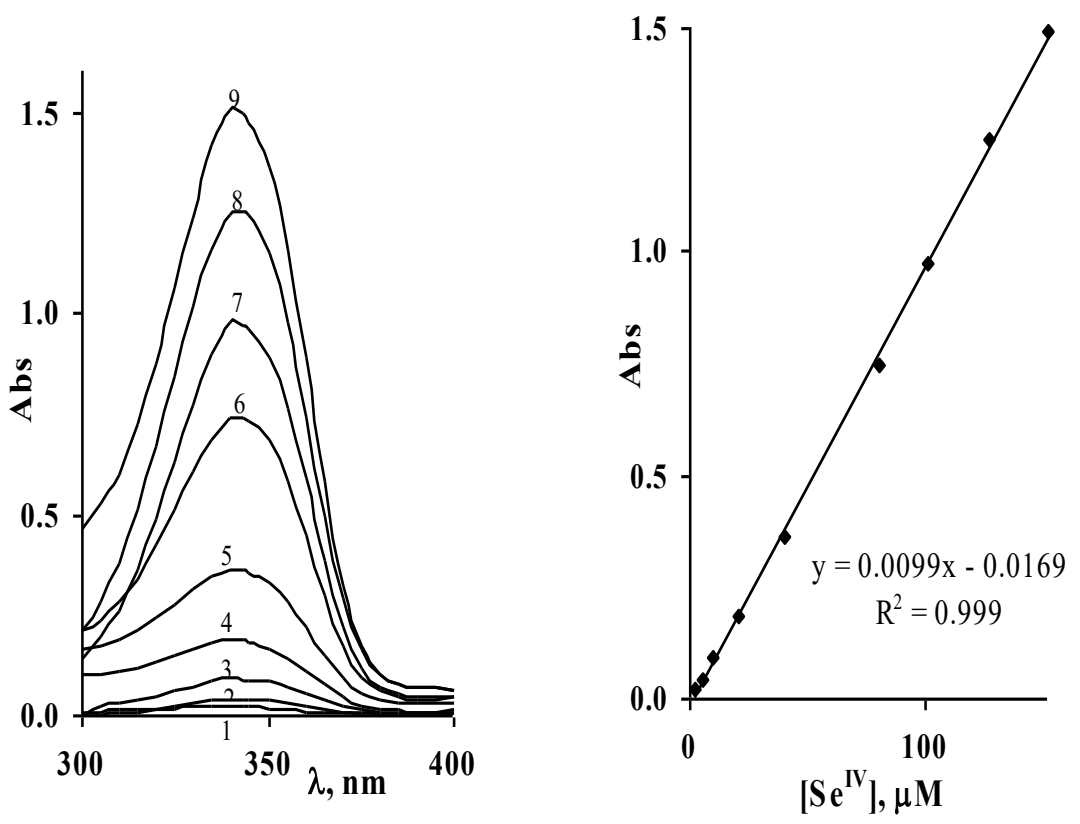

Figure 5. - Absorption spectra in varing Se concentration

The linear range between absorbance formed complex and Se concentration

Table.1. Analytical characteristics of method Parameters

\begin{tabular}{|c|c|}
\hline Wavelength / $\lambda_{\max }(\mathrm{nm})$, complex & 343 \\
\hline Wavelength / $\lambda_{\max }(\mathrm{nm})$, reagent & 260 \\
\hline Solvent & water \\
\hline Time / min & 30 \\
\hline Temperature $/{ }^{\circ} \mathrm{C}$ & $25 \pm 40^{\circ} \mathrm{C}$ \\
\hline Mole of reagent required mole of metal ion for full color developed & 100 Fold \\
\hline Composition of complex as obtained in Job's and molar ratio methods (M:L) & $1: 1$ \\
\hline Molar absorption Coefficient/ $\mathrm{L} \mathrm{mol}^{-1} \mathrm{~cm}^{-}$ & $0.5 \times 10^{4}$ \\
\hline Linear range $/ \mu \mathrm{g} \mathrm{mL}^{-1}$ & $0.2-15$ \\
\hline Detection limit $/ \mu \mathrm{g} \mathrm{mL}^{-1}$ & 0.05 \\
\hline Sandell's Sensitivity $/ \mu \mathrm{gcm}^{-2}$ & 0.031 \\
\hline Relative Standard Deviation & $0.19-1.60$ \\
\hline Regression Co-efficient & 0.999 \\
\hline Slope & 0.0099 \\
\hline
\end{tabular}

calculated and showed in Table 2 . The values of relative standard deviations for different concentrations of Se determined from the calibration curves. These results of accuracy and precision show that the proposed method have good repeatability and reproducibility. The lower values of relative standard deviation ( $\%$ ) and percentages of error indicated the high accuracy of the method. 
Table 2. Accuracy and precision for the determination of Se in pure soluation

\begin{tabular}{|c|c|c|c|c|c|c|}
\hline \multicolumn{3}{|c|}{$\left[\mathbf{S e}^{+4}\right], \boldsymbol{\mu} \mathbf{M}^{*}$} & \multirow{2}{*}{ RSD \% } & \multirow{2}{*}{$\begin{array}{l}\text { Confidence limit } \\
\mathbf{C L}_{\mathbf{9 5} \%} \mathbf{\mu M}\end{array}$} & \multirow{2}{*}{$\mathrm{ASE}, \boldsymbol{\mu M}$} & \multirow{2}{*}{ Recovery \% } \\
\hline Taken & Found $^{\mathrm{a}}$ & $\mathrm{SD}$ & & & & \\
\hline 10 & 9.86 & 0.16 & 1.60 & $9.86 \pm 0.20$ & 0.07 & 98.57 \\
\hline 30 & 28.71 & 0.22 & 0.75 & $28.71 \pm 0.27$ & 0.10 & 95.69 \\
\hline 50 & 47.63 & 0.20 & 0.43 & $47.63 \pm 0.25$ & 0.09 & 95.27 \\
\hline 70 & 69.90 & 0.19 & 0.28 & $69.90 \pm 0.24$ & 0.09 & 99.86 \\
\hline 100 & 104.21 & 0.19 & 0.19 & $104.21 \pm 0.24$ & 0.09 & 104.21 \\
\hline
\end{tabular}

${ }^{\mathrm{a}}$ Five independent analyses.

\subsubsection{Effect of diverse ions}

The extent of interference by diverse ions was determined by measuring the absorbance of solutions containing $5 \mu \mathrm{g} / \mathrm{mL}$ of Se (IV) and various amounts of diverse ions. The criterion for an interference was an absorbance value varying by more than $\pm 2 \%$ from the expected value of selenium (IV) alone. The results presented in Table 3 show that a large excess of cations and anions which are usually associated in the determination of Se (IV), do not interfere.

Table 3. Tolerance limits of diverse ions in the determination of $5 \mu \mathrm{g} / \mathrm{mL}$ of selenium (IV).

\begin{tabular}{|r|c|l|c|}
\hline Ion Added & Tolerance limit $\boldsymbol{\mu g} / \mathbf{m L}$ & Ion Added & Tolerance limit $\boldsymbol{\mu g} / \mathbf{m L}$ \\
\hline $\mathrm{Fe}(\mathrm{II})$ & 125 & $\mathrm{Cd}(\mathrm{II})$ & 65 \\
\hline $\mathrm{Fe}(\mathrm{III})$ & 75 & $\mathrm{Ag}(\mathrm{I})$ & 225 \\
\hline $\mathrm{Hg}(\mathrm{II})$ & 160 & $\mathrm{~V}(\mathrm{~V})$ & 310 \\
\hline $\mathrm{Ni}(\mathrm{II})$ & 300 & Tartrate & 485 \\
\hline $\mathrm{Zn}(\mathrm{II})$ & 420 & Iodate & 302 \\
\hline $\mathrm{Mn}(\mathrm{II})$ & 285 & Urea & 288 \\
\hline $\mathrm{Cr}(\mathrm{III})$ & 300 & Citrate & 386 \\
\hline $\mathrm{Ca}(\mathrm{II})$ & 400 & Bicarbonate & 423 \\
\hline $\mathrm{Ba}(\mathrm{II})$ & 380 & Sulphate & 368 \\
\hline $\mathrm{Cu}(\mathrm{II})$ & 600 & Oxalate & 257 \\
\hline $\mathrm{NI}(\mathrm{II})$ & 740 & Nitrate & 320 \\
\hline $\mathrm{Pb}(\mathrm{II})$ & 8.3 & Acetate & 189 \\
\hline
\end{tabular}

\subsubsection{Composition and stability constant of the complex}

Job's method of continuous variation and molar-ration methods were applied to ascertain the stoichiometric composition of the complex. It was found that DAUH forms 1:1 complex with Se (IV) as shown in the (Fig.6).

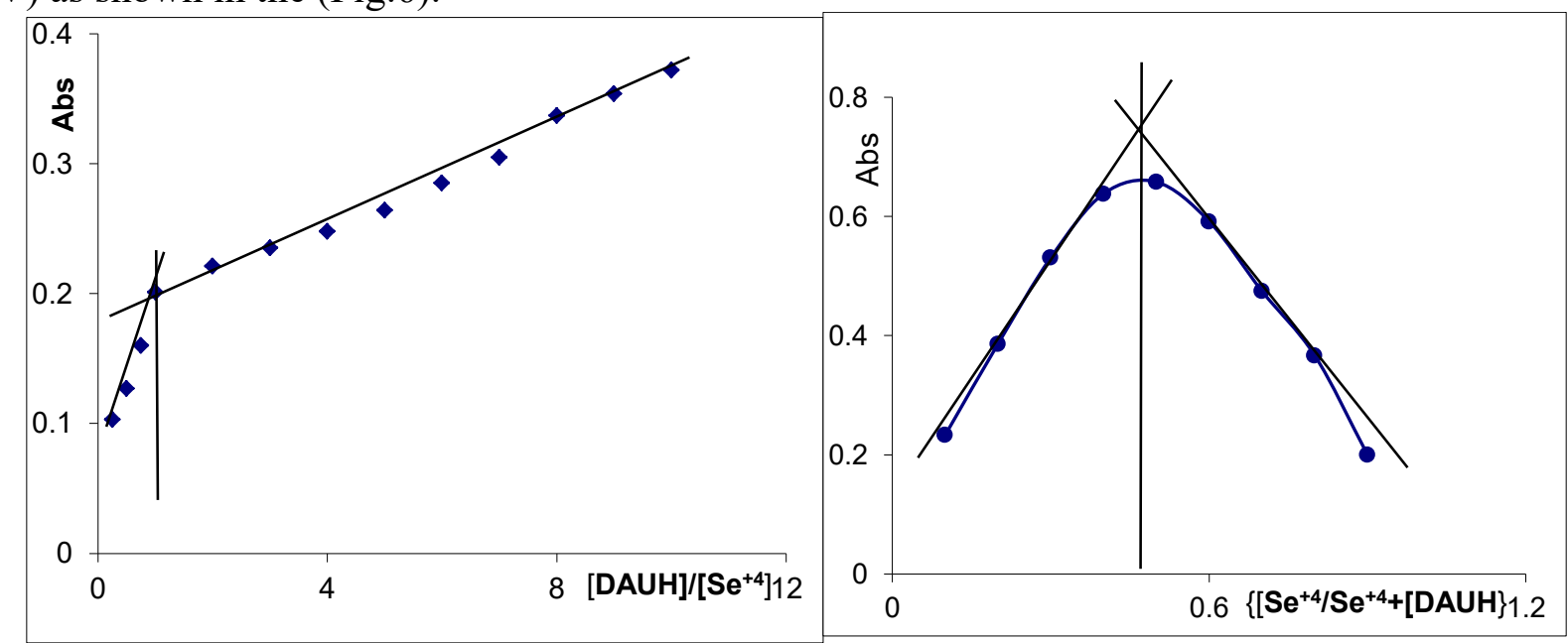

Figure.6. Continuous variation and molar-ration methods Se (IV)-DAUH. Se (IV) and DAUH, $1 \times 10^{-3} \mathrm{M}$ 


\subsubsection{Application}

The proposed spectrophotometric method is applied for the determination of Se (IV) in in various samples. A known aliquot of the above sample solutions were taken and the selenium content was determined as described is given in the general procedure, and the results of the suggested method were coincidental with the analysis data of the same samples with the Hydride Generation-Atomic Absorption technique as a comparative method. Table (4).

Table 4: Determination Se(IV) in various samples

$$
\mathrm{n}=5, \alpha=0.95
$$

\begin{tabular}{|l|c|c|c|c|}
\hline \multirow{2}{*}{\multicolumn{1}{c|}{ Samples }} & \multicolumn{2}{|c|}{$\begin{array}{c}\text { Results of } \\
\text { HG-AAS }\end{array}$} & $\begin{array}{c}\text { Results of proposed } \\
\text { method }\end{array}$ \\
\cline { 2 - 5 } & $\begin{array}{c}\bar{X} \pm \Delta \mathbf{\Delta X} \\
\mathbf{p p m}\end{array}$ & $\begin{array}{c}\text { RSD } \\
\mathbf{\%}\end{array}$ & $\begin{array}{c}\bar{X} \pm \Delta \mathbf{\Delta X} \\
\mathbf{p p m}\end{array}$ & $\begin{array}{c}\text { RSD } \\
\mathbf{\%}\end{array}$ \\
\hline Water & $0.534 \pm 0.032$ & 1.85 & $0.552 \pm 0.012$ & 1.12 \\
\hline Yellow Corn & $0.691 \pm 0.019$ & 2.20 & $0.700 \pm 0.020$ & 0.68 \\
\hline Peas & $0.730 \pm 0.011$ & 1.20 & $0.746 \pm 0.002$ & 0.04 \\
\hline Chick-pea & $0.782 \pm 0.009$ & 0.90 & $0.745 \pm 0.021$ & 0.59 \\
\hline Wheat & $0.950 \pm 0.005$ & 0.40 & $0.931 \pm 0.001$ & 0.04 \\
\hline Almond & $1.190 \pm 0.022$ & 1.50 & $1.112 \pm 0.227$ & 1.24 \\
\hline Concentrated forage of chickens (1) & $0.890 \pm 0.002$ & 0.20 & $0.854 \pm 0.013$ & 0.31 \\
\hline Concentrated forage of chickens (2) & $0.991 \pm 0.012$ & 1.00 & $0.997 \pm 0.046$ & 0.95 \\
\hline Over-concentrated forage of chickens & $16.000 \pm 0.654$ & 3.30 & $15.183 \pm 0.477$ & 0.33 \\
\hline Stannous metal (Egg hen) & $19.850 \pm 0.246$ & 1.00 & $20.501 \pm 0.042$ & 0.68 \\
\hline Syravite E (Liquid solution) & $0.670 \pm 0.012$ & 1.40 & $0.691 \pm 0.420$ & 0.54 \\
\hline Syravite E + Selenium powder & $0.811 \pm 0.007$ & 0.70 & $0.7911 \pm 0.280$ & $0.21 \mathrm{~s}$ \\
\hline
\end{tabular}

\section{CONCLUSION}

The author has introduced a new sensitive reagent DAUH for the direct spectrophotometric determination of trace amounts of Se (IV). The proposed spectrophotometric method is simple, highly sensitive and selective for the determination of Se (IV) in water and soil samples when compared with other spectrophotometric methods. The proposed method is simple, rapid and common metal ions such as $\mathrm{Fe}^{3+}, \mathrm{Pb}^{2+}, \mathrm{Co}^{2+}, \mathrm{Ni}^{2+}, \mathrm{Zn}^{2+}, \mathrm{Mn}^{2+}, \mathrm{Cr}^{3+}$ do not interfere. It also offers advantages like reliability and reproducibility in addition to its simplicity instant color development and less interference effect. The results obtained through UV-Visible spectrophotometer have been compared with those obtained through the HG-AAS. The method has been successfully applied for the determination of selenium in various samples.

\section{References}

[1] Holok N, Speechio J. J., Analyst. 199 (1994) 2179-2182.

[2] Manish R, Ramachandran K. N; Gupta V. K., Talanta. 41 (1994) 1623-1626.

[3] Agarwal D, Sunitha G; Gupta V. K., Indian. Chem. Soc. 73 (1998) 151-154.

[4] Safavi A, Afkhami A., Anal. Lett. 28 (1995) 1095-1101.

[5] Pathare M. N, Sawant A. D., Anal. Lett. 28(1995) 317-334.

[6] Pyrzynsaka K., Anal. Sci., 13(1997) 629-632.

[7] Revanasiddappa H. D, Kiran Kumar T. N., Anal. Sci., 17 (2001) 1309-1312.

[8] Bem E. M., Chem. Anal (Warsaw). 197924155. 
[9] Zingaro R. A. \& W. C. Cooper, Selenium, Van Nostrand Reinhold, New York, 1974, 594.

[10] Rosenfeld J, Beath 0. A., Selenium. Academic Press, New York, 1964.

[11] Thomson CD, Eur. J. Clin Nutr., 58 (2004) 391-402.

[12] Goldhaber SB., Regulatory Toxicology and Pharmacology. 38(2003) 232-42.

[13] Combs G. F, J. r \& Gray WP., Pharmacol .Ther., 79 (1998) 179-92.

[14] McKenzie R. C, Rafferty T. S, Beckett G. J., Immunol Today. 19(1998) 342-5.

[15] Levander O. A., J. Nutr., ,127(1997) 948S-50S.

[16] Arthur J. R, Can J Physiol Pharmacol. 69(1991) 1648-52.

[17] Patty F. A., Industrial Hygiene and Toxicology (Wiely,New York). 19622886.

[18] Shamberger R. J., Biochemistry of Selenium (Plenum Press, NewYork). 1983.

[19] West P W \& Shendrikar A. D., Anal Chim Acta. 197782403.

[20]Shapira J. R., Organic Selenium Compound their Chemistry and Biology. (Wiely Interscience, NewYork) 1971703.

[21] Jeffrey A. H, Roger G. B, Carolyn A, G, J AOAC Ibt.1992 75269.

[22] Stewart, Chow A., Talanta. 1993401345.

[23] Hao D Q ,Hang G. Z, Zhang Y. M ,Tian G .J.,Talanta. 199643595.

[24] Macleod B. A, Shand C. A.,Talanta. 1996, 43, 1091. 